\title{
Modeling Operational Parameters of a Reactive Electro-Dialysis Cell for Electro-Refining Anodic Scrap Copper*
}

\author{
Gerardo Cifuentes, José Hernández, Jorge Manríquez, Nicolas Guajardo \\ Department of Metallurgical Engineering, Universidad de Santiago de Chile, Santiago, Chile \\ Email: gerardo.cifuentes@usach.cl
}

Received 20 August 2014; revised 5 October 2014; accepted 22 October 2014

Copyright (C) 2014 by authors and Scientific Research Publishing Inc.

This work is licensed under the Creative Commons Attribution International License (CC BY). http://creativecommons.org/licenses/by/4.0/

cc) (i) Open Access

\begin{abstract}
This work will create an electro-dialysis cell model that has the purpose of refining anodic scrap copper-an element that currently must be returned to the copper conversion process. The cell modeling is based on Ohm's Law, while the resulting copper deposit morphology is studied through the thickness of the layer deposited on the surface and the electric current lines traced from the anode to the cathode. The use of the model demonstrated that it is possible to effectively predict the specific energy consumption required for the refinement of the anodic scrap copper, and the morphology of the cathode obtained, with a margin of error of $9 \%$.
\end{abstract}

\section{Keywords}

Electro-Refining, Modeling, Copper Scrap, Reactive Electro-Dialysis, Specific Consumption

\section{Introduction}

The objective of copper electro-refining process is the electrochemical dissolution of an impure anode (98\% $\mathrm{Cu})$ to obtain a cathode with $99.99 \%$ pure copper [1]-[3]. After a number of electro-refining processes copper anodes should be removed from the electrolytic refining cells without completely dissolving for 2 reasons.

First, the anode section that is dissolved is only the one immersed in the electrolyte. The anode cannot be completely immersed due to the electrical connection with the power source. If the latter is immersed, it would dissolve along with the anode and the process would stop.

The second one that prevents the scrap from dissolving is the quality of the copper deposit: if the cathode is not morphologically regular, its mechanical properties (hardness, resistance, etc.) will be very low, and therefore

\footnotetext{
"Modeling operational parameters of a reactive electro-dialysis cell for electro-refining anodic scrap copper.

How to cite this paper: Cifuentes, G., Hernández, J., Manríquez, J. and Guajardo, N. (2014) Modeling Operational Parameters of a Reactive Electro-Dialysis Cell for Electro-Refining Anodic Scrap Copper. American Journal of Analytical Chemistry, 5, 1011-1019. http://dx.doi.org/10.4236/ajac.2014.515107
} 
will not be capable of continuing with the following processes. To obtain a high-quality cathode, the anode's surface must be as homogeneous as possible so it does not produce preferential deposits on the cathode. Because the scrap copper anode is not morphologically regular, the cathode resulting of this process would have a bad quality surface.

Consequently, the result of an eventual electro-refining using scrap would result in a cathode unfit for the following stages. In practical terms, this problem represents a percentage of copper which cannot leave the circuit; that is, a circulating charge within the process.

The authors [4]-[6] have worked with an electro-dialysis system to minimize the scrap re-circulation to the smelting process. Stainless steel baskets are used as supporting electrodes to provide electrical connection of the system because, as in the case of scrap copper anodes, morphologically irregular metals are usually used. Using a basket results in high-quality surface, regardless of the morphology of the metal put inside. Therefore, this electrode support shall be used to dissolve scrap copper anode. In parallel they use an electro-dialysis cell to separate both electrodes (anode and cathode). The reason for this is the constant generation of the anode slime inside the stainless steel basket. The accumulation of slime decreases the electrical contact inside the anode, increasing the potential system consumption gradually to the point of corroding the stainless steel and stopping the process.

The modeling of process is a very important tool of knowledge; with this tool it is possible to present several scenarios to study the reality. In this work, experimental data compiled for the authors are used; all the data above-mentioned are necessary like input to the equations for characterizing the system. Then it works with COMSOL Multiphysics program to modeling the operational parameters of the electro-dialysis cell used for electrorefining of anodic scrap copper.

\section{Theory}

\subsection{Nernst-Planck Equation}

The equation which models the flow of ions along the electrolyte is the Nernst-Planck equation, showing that the flow may be due to 3 different mechanisms: diffusion, migration or convection (Equation (1)) [7].

$$
N_{i}=-D_{i}\left[\frac{\mathrm{d} c_{i}}{\mathrm{~d} x}+z_{i} c_{i} \cdot \frac{F}{R \cdot T} \cdot \frac{\mathrm{d} \varphi}{\mathrm{d} x}\right]+c_{i} v
$$

where

- $N_{i}$ : total flow of ions in a solution by unit of area and time.

- $-D_{i} \cdot \frac{\mathrm{d} c_{i}}{\mathrm{~d} x}$ : ion flow by diffusion.

- $-D_{i} \cdot z_{i} \cdot c_{i} \cdot \frac{F}{R \cdot T} \cdot \frac{\mathrm{d} \varphi}{\mathrm{d} x}$ : ion flow by migration.

- $c_{i} v$ : ion flow by convection.

The Nernst-Planck shows that the ion flux in any of the systems may be due to any of the 3 aforementioned driving forces: diffusion, convection and migration. In normal working conditions, these working cells have a constant concentration of copper throughout the solution. The cell's agitation is also very low. Consequently it can be assumed with a certain degree of precision that the ions in the solution are moved by the sole difference of potential applied, that is, migration. In this way the equation Nernst-Plank is reduced to the Ohm Law, Equation (2):

$$
i=\sigma \cdot \nabla \varphi
$$

where $\sigma$ is ionic conductivity of the solution, $i$ is the current density that is conducted through the cell, and $\nabla$ is the difference in applied potential using the DC power source. In this way, the decrease in the electrolyte potential and the cell's membrane will be given by the value of their conductivity in $\mathrm{S} / \mathrm{m}$.

\subsection{Electrode Kinetics}

Electrode kinetics allows determining the over potential, $\mu$, that must be applied to the electrodes for a given current density. 
Electrode kinetics is represented based on the Butler-Volmer equation (Equation (3)) [8].

$$
i_{b-v}=i_{0} \cdot\left(\exp \left[\frac{\alpha \cdot n \cdot F \cdot \mu}{R \cdot T}\right]-\exp \left[\frac{-\beta \cdot n \cdot F \cdot \mu}{R \cdot T}\right]\right)
$$

where $i_{b-v}$ is the working current density value for a mixed kinetic control, $i_{0}$ is the exchange current density, $\alpha$ and $\beta$ are the kinetic reaction parameters, $n$ is the oxidation state of the ion, $T$ is temperature and $R$ is the universal constant of gases.

Nevertheless, it is known that in industrial processes, kinetics of most electro-chemical processes work with mixed control, that is, they depend on the mass transfer as much as they do on the charge. Electrode kinetics are represented by the Equation (4):

$$
i_{m}=\frac{i_{\lim } \cdot i_{b-v}}{i_{\lim }+i_{b-v}}
$$

where $i_{\lim }$ is the system's limit current density and $i_{m}$ is the working current density for mixed control kinetics.

In the case of porous electrodes, the use of correction factors is very common to consider the decrease in effective conductivity inside the porous electrode, due to the loss of its real volume-in electrode or electrolyteor because of the decreased convection inside the porous electrode due to its inner ruggedness.

The most common correction is known as the Bruggeman coefficient, which considers the effective volume of the supporting electrodes, in this case, the stainless steel basket and the electrolyte inside it. This way, the effective conductivity of the supporting electrode and the electrolyte inside the porous electrode will be given by the Equations (5) and (6).

$$
\begin{aligned}
& i_{l}=-\sigma_{i, \text { eff }} \cdot \nabla \varphi_{l}, \sigma_{l, \text { eff }}=\epsilon_{l}^{1.5} \cdot \sigma_{l} \\
& i_{s}=-\sigma_{s, e f f} \cdot \nabla \varphi_{s}, \sigma_{s, \text { eff }}=\epsilon_{s}^{1.5} \cdot \sigma_{s}
\end{aligned}
$$

where the subindexes $l$ and $s$ are supporting electrolyte and electrode, while $\sigma_{l, \text { eff }}$ and $\sigma_{s, \text { eff }}$ are their effective conductivities and $\epsilon_{l}$ and $\epsilon_{s}$ their volume, respectively. This results in the value of the overpotential of the representative electrode of the real case.

\section{Cell Modelling}

The diagram of Figure 1 represents the work system and the main components.

The used work cell is shown in Figure 2. Here it shows that the cathode corresponds to a vertical stainless steel sheet, whereas for the anode a support basket was used to dissolve the anodic scrap copper it contains. The basket is considered a porous electrode.

The modeling of the cell will be carried out using the COMSOL Multiphysics program in its version 4.3b [9].

First, the properties of the work cell for modeling must be defined. The cell will be shown in Figure 3.

The work cell dimensions are the following: Each half cell shown in Figure 3 is $5 \times 7.5 \times 8 \mathrm{~cm}^{3}$ in dimension. The actual work area is $5 \times 7.5 \mathrm{~cm}^{2}$, while the flow which enters the electrolyte within each half-cell is $1.8 \mathrm{~mL} / \mathrm{s}$.

Thus, the cell shown in Figure 3 is represented in COMSOL Multiphysics according to Figure 4.

Having defined the geometry of work (Figure 4), we proceed to define the sub-domains and boundary conditions:

Electrolyte and membrane: cupric ions are transported through them. Therefore, these sub-domains will be defined through Ohm's law and its ionic conductivity.

Cathode: in the cathode, the cathode current density must be known, so that the thickness of copper deposited on the surface to be calculated using Faraday's law, as well as the electrode kinetics, to determine the overpotential need to be applied to the electrode.

Anode: the anode is made up of the stainless steel basket, the scrap copper to be dissolved, and the electrolyte therein. To consider the presence of all these elements, the anode will be characterized as a porous electrode, and their respective volume percentages shall decrease the effective conductivity of the electrode. Finally, their kinetic parameters obtained from voltammetry curves are entered. 


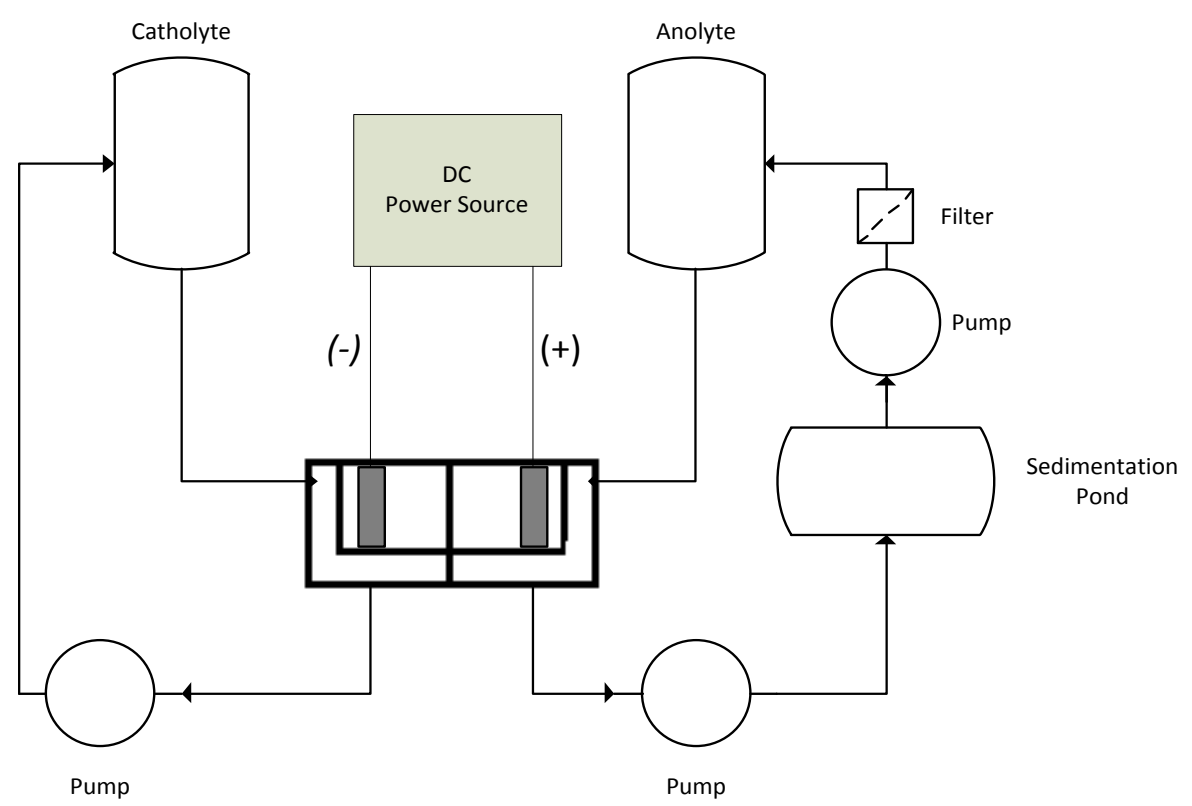

Figure 1. Diagram of the system used.

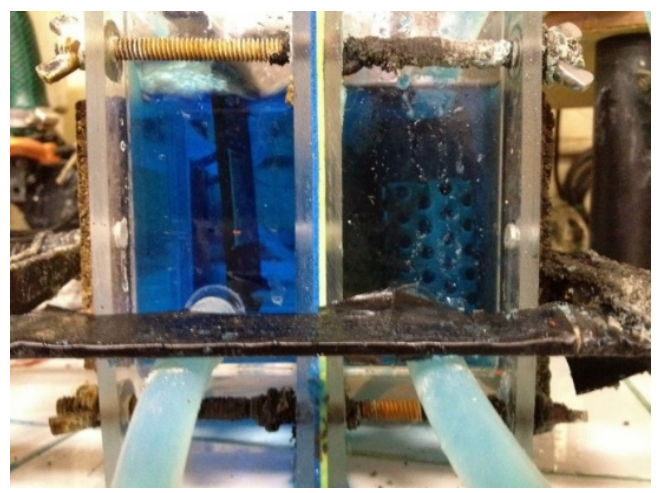

Figure 2. Used work cell.

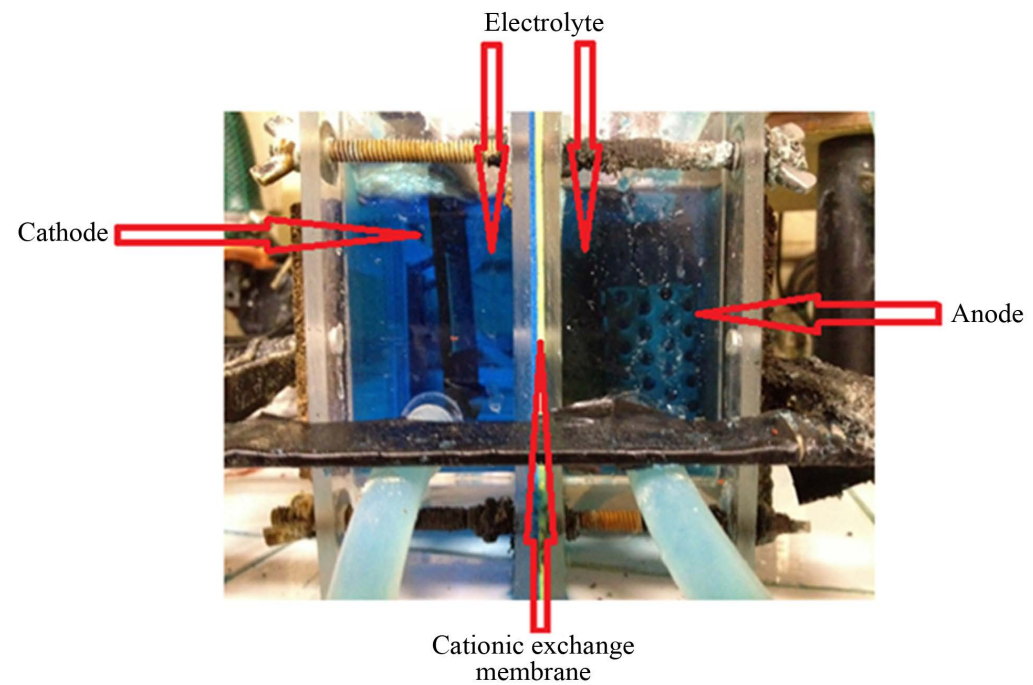

Figure 3. Work cell to be modeled. 
Electric insulation: all outside edges of the work cell are acrylic, which is an insulating material. Therefore, the current flowing to the outside of the cell is zero. Mathematically this is expressed by the Equation (7):

$$
-n * i=0
$$

where $n *$ is the vector corresponding to the normal direction of the cell walls.

Afterwards, the importance of the existing flow inside the basket and the temperature of the system must be evaluated. For this, experimental voltametry curves were drawn for different working conditions. The results are shown in Figure 5.

From Figure 5 it can be seen that the best working condition is when the agitation of the cell and the temperature are at their highest value. Similarly, the cathodic voltammetry at $40^{\circ} \mathrm{C}$ was also plotted, Figure 6 .

The kinetic parameters of each electrode are determined by the data obtained in Figure 5 and Figure 6.

Table 1 shows the experimental parameters of the work cell used for modeling.

\section{Results}

The results obtained of the model cell are as follows:

Figure 7 illustrates how the potential drops in the cell as the distance toward the cathode decreases. From this point an important observation is made: in general, it can be seen that the potential drop is constant throughout the cell, with two exceptions: the first occurs inside the porous electrode. The reason for this is the difficulty for the electrolyte to move inside, in other words, a reduction in convective transport mechanism occurs, which must be compensated with an increase of the potential difference which must be applied. The second point where a sharp potential drop occurs is in the domain of the membrane [10]-[12]. As noted, the only difference

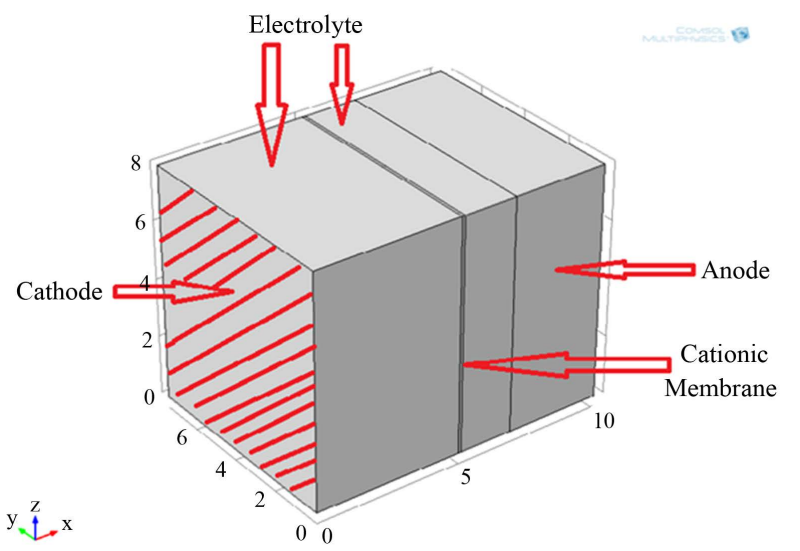

Figure 4. Representation of the cell in COMSOL Multiphysics 4.3b.

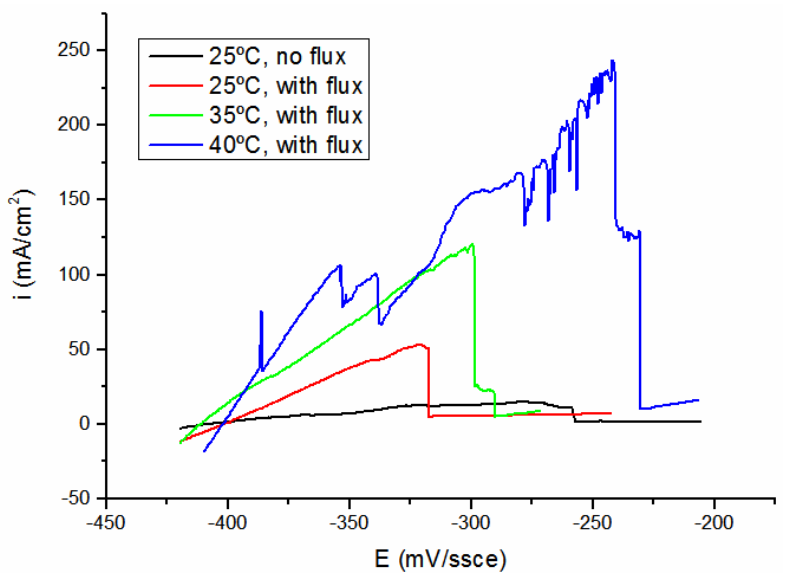

Figure 5. Experimental linear voltametry drawn for the anode in different working conditions. 
Table 1. Experimental parameters used for modelling the cell [4].

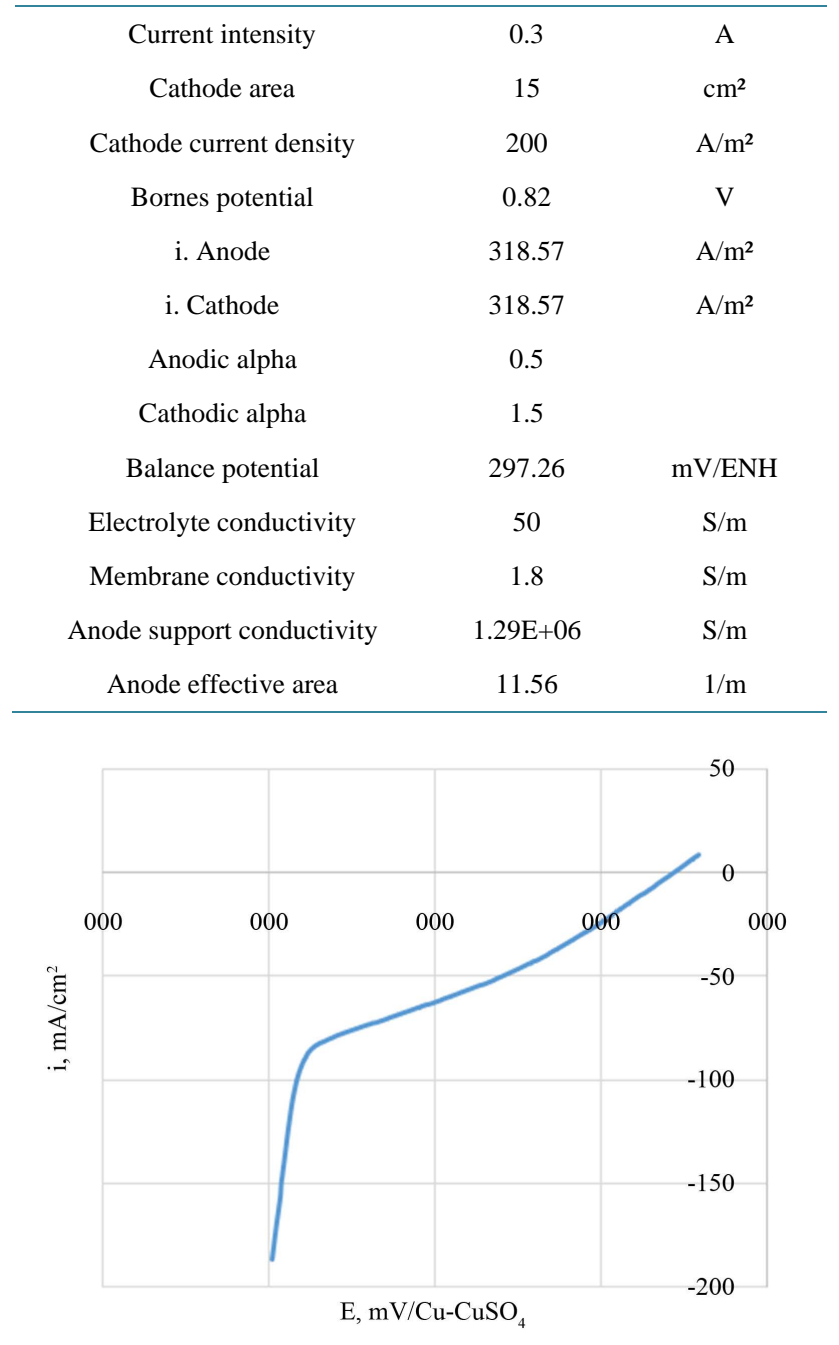

Figure 6. Experimental linear voltammetry drawn for the cathode, $40^{\circ} \mathrm{C}$.

Time $=0$ Slice: Electrolyte potential $(\mathrm{mV})$

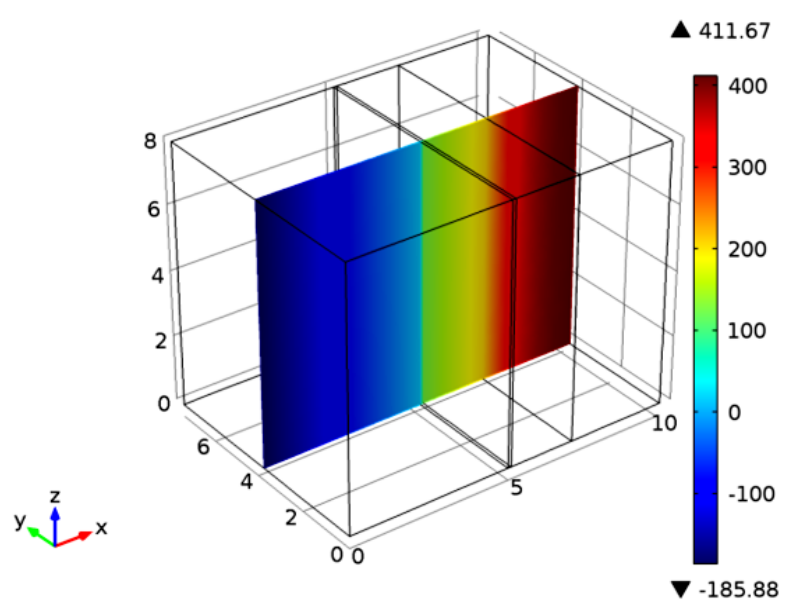

Figure 7. Decrease in potential throughout the electrolyte. 
between this and the electrolyte is each one's conductivity. As this property is much lower in the membrane, it is necessary to apply a greater amount of energy compared to the rest of the electrolyte.

To solve each of these important potential drops in the electrolyte, the stirring conditions within the porous electrode must improve so that the ion transport is not hindered by convection. Regarding the membrane, the solution is to design it as thin as possible and with the largest cross-sectional area, but not to the point of fragility, as these are made of polymers, or to improve its conductivity.

Figure 8 and Figure 9 illustrate the anodic and cathodic overpotentials applied to the working electrodes. These points are important because in many cases are very important fractions of the Bornes potential applied to the cell terminals.

It can be seen that the cathode overpotential is the same throughout the electrode, while this parameter varies on the anode. This is due to the nature of the flow, which is constant throughout the cross-sectional area. For the anode, the system must provide energy as it moves away from the area over which the electrical connection is made, due to the potential drop product of the tortuosity the porous electrode produces in the flow of electrolyte inside.

Figure 10 shows 2 important characteristics: The morphology of the copper deposits and the current lines transported by the $\mathrm{Cu}^{2+}$ ions. These 2 variables define the morphology of the deposit to be obtained on the cathode. Recalling that the current always preferentially uses the paths that offer least resistance for transport, in this type of testing this effect will be reflected in a higher deposit in some sections than in others.

The same figure shows that the cathode surface is parallel to the porous electrode. As a result, the deposit is practically homogeneous in all its dimensions. Additionally, the importance of using support electrodes for the field of electroplating is also noted: thanks to them, the morphology of the metal to be dissolved for any type of coating is irrelevant since the supporting electrode is responsible for distributing the current lines evenly, as shown in Figure 10. For industrial application, this effect is very important, since electro-refining scrap has very irregular morphology, resulting in a very irregular cathodic deposition, however, this problem is solved with the anodic support.

\section{Validation of Results}

The experimental data obtained from the cell can be compared with that predicted by the modeling in Table 2 .

Table 2 shows that it is possible to obtain representative values of the data obtained experimentally.

\section{Conclusions}

It can be seen that modeling can be very useful to understand and improve the operation of electrochemical systems. However, from unit 3 it can be concluded that the modeling of such systems cannot be simulated in any case without performing measurements to the system itself, since most of the parameters used were measured after the system was underway.

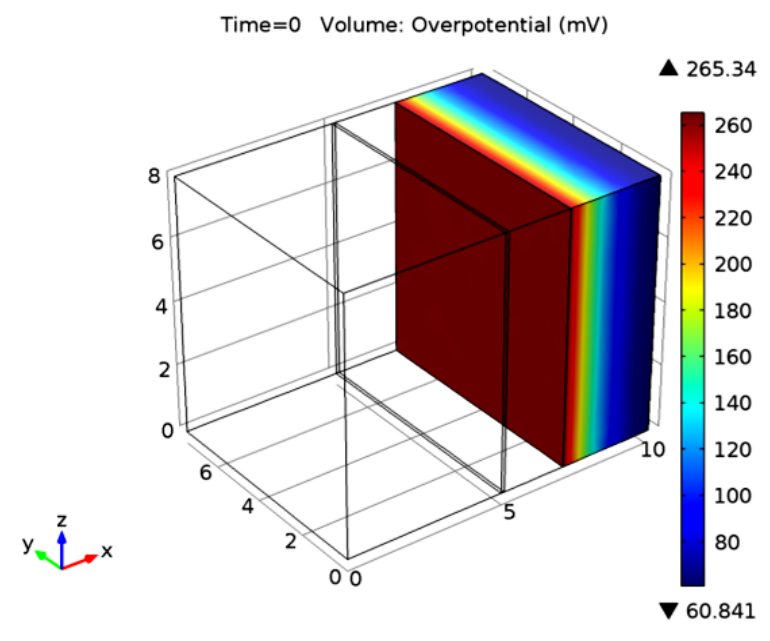

Figure 8. Anodic overpotential. 
Table 2. Comparison between experimental data and modeling.

\begin{tabular}{ccc}
\hline Potential drop mV & Experimental data & $\begin{array}{c}\text { Modeling with } \\
\text { correction }\end{array}$ \\
\hline Anodic overpotential. & 250 & 265 \\
Cathodic overpotential. & 40 & 33 \\
Electrolyte and membrane & 530 & 597 \\
Bornes potential & 820 & 895 \\
Relative error & & $9 \%$ \\
\hline
\end{tabular}

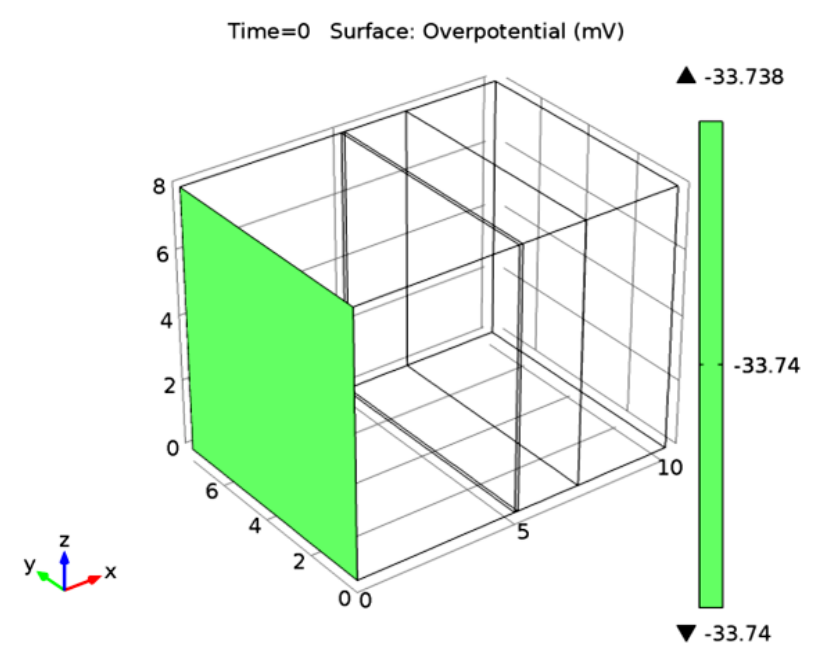

Figure 9. Anodic overpotential.

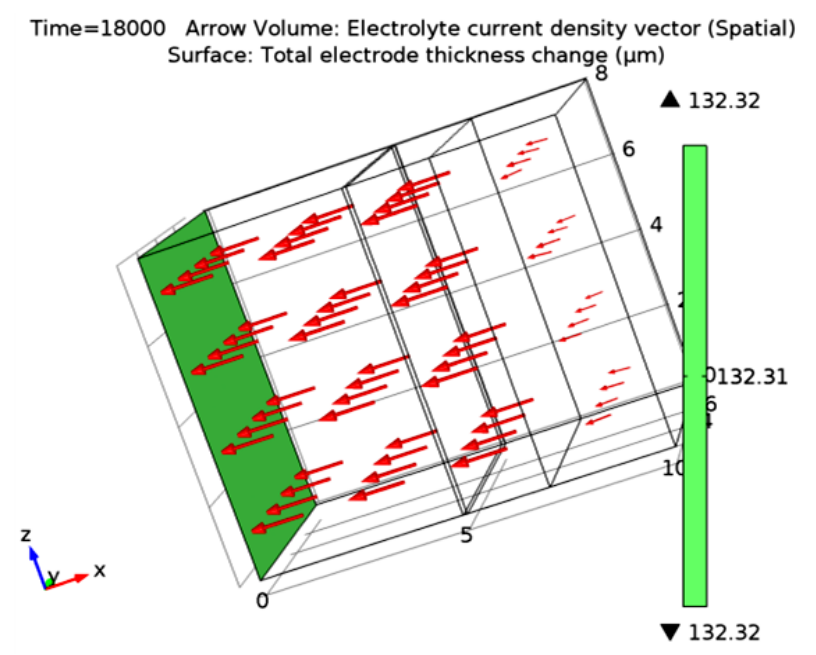

Figure 10. Anodic overpotential.

From modeling and system simulation work it is concluded that the best way to reduce energy consumption would be to improve the conditions of agitation inside the basket, since the loss of convection was caused by the very presence of copper scrap in the stainless steel basket, forcing the system to apply great anode overpotential and potential drop within the electrolyte.

Finally, another efficient alternative is to use a membrane that has better conductivity than that used in this experiment, since the latter in particular represented a significant decrease in potential. 


\section{Acknowledgements}

Support of this work by DICYT of the Universidad de Santiago de Chile is gratefully acknowledged.

\section{References}

[1] Cifuentes, G. (2000) Theory and Praxis of Electrometallurgy (Teoría y práctica de la electrometalurgia). Class Notes, Metallurgical Department at University of Santiago of Chile, Santiago.

[2] Urra, C. (2003) Electrolytic Refining of Particulate Anodic Scrap (Refinación electrolítica de scrap anódico particulado). Titulation Work, Metallurgical Department, University of Santiago of Chile, Santiago.

[3] Davenport, G., King, M., Schlesinger, M. and Biswas, A.K. (2002) Extractive Metallurgy of Copper. 3rd Edition, Elsevier, Oxford.

[4] Cifuentes, G., Hernández, J. and Guajardo, N. (2014) Recovering Scrap Anode Copper Using Reactive Electrodialysis. American Journal of Analytical Chemistry, 5, 9.

[5] Hernández, J. (2014) Anodic Scrap Recovering Using Reactive Electrodialysis (Recuperación de Scrap anódico por electrodiálisis reactiva). M.Sc. Thesis, Metallurgical Department, University of Santiago of Chile, Santiago.

[6] Cifuentes, G., Simpson, J., Lobos, F., Briones, L. and Morales, A. (2009) Copper Electrowinning Based on Reactive Electrodialysis. Journal of the Chilean Chemical Society, 54, 334-338. http://dx.doi.org/10.4067/S0717-97072009000400002

[7] Walsh, F. (1999) A First Course of Electrochemical Engineering (Un primer curso de Ingeniería Electroquímica). Editorial Club Universitario, San Vicente, España.

[8] Bockris, J. and Reddy, A. (1977) Modern Electrochemistry: An Introduction to an Interdisciplinary Area, Volume 2. 3th Edition, Plenum Rosetta Edition, New York.

[9] Introduction to COMSOL Multiphysics. http://www.comsol.com/shared/downloads/IntroductionToCOMSOLMultiphysics.pdf

[10] Xu, T.W. (2005) Ion Exchange Membranes: State of Their Development and Perspective. Journal of Membrane Science, 263, 1-29. http://dx.doi.org/10.1016/j.memsci.2005.05.002

[11] Baker, R.W. (2004) Membrane Technology and Applications. 2nd Edition, Membrane Technology and Research, Inc., Menlo Park, California. http://dx.doi.org/10.1002/0470020393

[12] Davis, S.M. (2006) Electrochemical Splitting of Sodium Sulfate. M.Sc. Thesis, Georgia Institute of Technology, Atlanta, Georgia. 
Scientific Research Publishing (SCIRP) is one of the largest Open Access journal publishers. It is currently publishing more than 200 open access, online, peer-reviewed journals covering a wide range of academic disciplines. SCIRP serves the worldwide academic communities and contributes to the progress and application of science with its publication.

Other selected journals from SCIRP are listed as below. Submit your manuscript to us via either submit@scirp.org or Online Submission Portal.
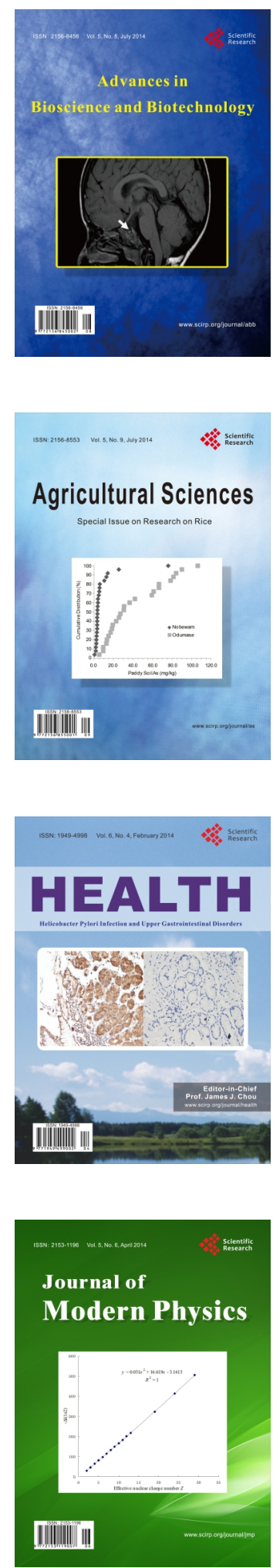
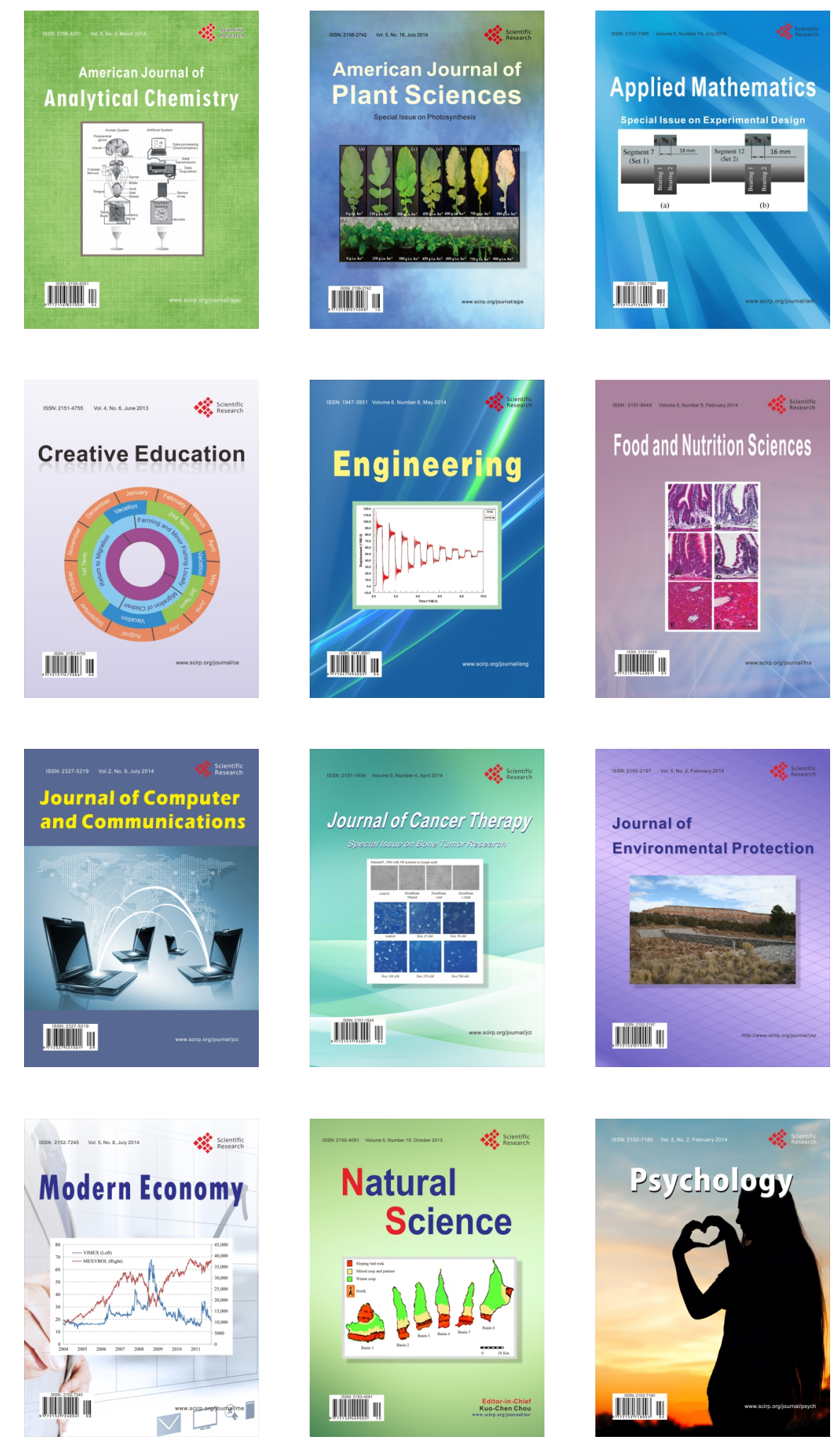